\title{
Fabrication of paclitaxel hybrid nanomicelles to treat resistant breast cancer via oral administration
}

This article was published in the following Dove Press journal:

International Journal of Nanomedicine

\section{Ling-Hui Dian ${ }^{1,2, *}$ \\ Ying-Jie $\mathrm{Hu}^{1, *}$ \\ Jia-Ye Lin' \\ Jing-Ying Zhang' \\ Yan Yan' \\ Yi-Nuo Cui' \\ Zhan-Bo Su' \\ Wan-Liang Lu'}

'State Key Laboratory of Natural and Biomimetic Drugs, School of Pharmaceutical Sciences, Peking University, Beijing, ${ }^{2}$ School of Pharmaceutical Sciences, Guangdong Medical University, Dongguan, China

*These authors contributed equally to this work
Correspondence: Wan-Liang Lu State Key Laboratory of Natural and Biomimetic Drugs, School of Pharmaceutical Sciences, Peking University, 38 Xueyuan Road, Beijing 100191, China

Tel/fax +86 I0 82802683

Email luwl@bjmu.edu.cn

\begin{abstract}
Aim: Oral chemotherapy using anticancer drugs would improve the clinical practice and the life quality of patients. The aim of the present study was to develop paclitaxel hybrid nanomicelles for oral administration to treat resistant breast cancer.

Methods: Evaluations were performed on human breast cancer MCF-7 cells, drug-resistant breast cancer MCF-7/Adr cells, and in MCF-7/Adr-xenografted BALB/c nude mice. The nanomicelles were composed of the polymer soluplus, $d-\alpha$-tocopheryl polyethyleneglycol 1000 succinate $\left(\right.$ TPGS $\left._{1000}\right)$, and dequalinium (DQA). The constructed paclitaxel hybrid nanomicelles were $\sim 65 \mathrm{~nm}$ in size.
\end{abstract}

Results: The nanomicelles improved cellular uptake and anticancer efficacy in the resistant breast cancer cells and induced mitochondria-mediated apoptosis. The mechanism of the apoptosis-inducing effect was related to the co-localization of the nanomicelles with mitochondria; the activation of pro-apoptotic protein Bax, cytochrome C, and apoptotic enzymes caspase 9 and 3; and the inhibition of anti-apoptotic proteins Bcl-2 and Mcl-1. Oral administration of paclitaxel hybrid nanomicelles had the same anticancer efficacy as the intravenous injection of taxol in resistant breast cancer-bearing mice. The oral suitability of this formulation was associated with the nanostructure and the actions of TPGS ${ }_{1000}$ and DQA.

Conclusion: The fabricated paclitaxel hybrid nanomicelles could provide a promising oral formulation to treat drug-resistant breast cancer.

Keywords: paclitaxel, nanomicelles, oral, drug-resistant breast cancer, mice

\section{Introduction}

Chemotherapy plays a crucial role in eliminating cancer cells during clinical treatment. Most chemotherapeutic agents are only given by intravenous administration, while an oral administration of an anticancer drug could be greatly beneficial for the patients. For example, a patient with breast cancer who has received comprehensive treatment in hospital still needs to receive chemotherapy after being discharged from the hospital. Accordingly, oral administration, rather than intravenous injection, would be an optimal choice. Oral chemotherapy is a key step toward chemotherapy at home, and the development of oral anticancer drugs would improve the clinical practice and the life quality of patients. Most clinically used anticancer agents are not suitable for oral administrations because of their poor absorption via the gastrointestinal tract. Therefore, how to develop oral administration of the anticancer drugs remains an unsolved scientific issue in the treatment of breast cancer.

Paclitaxel is a broad-spectrum anticancer drug that is effective in treating various solid tumors, such as breast cancer and ovarian cancer. ${ }^{1-3}$ In clinical treatment, paclitaxel is administered intravenously as a formulation containing dehydrated alcohol and a surfactant (cremophor EL). The main issues concerning the clinically used paclitaxel 
formulation are that administration of paclitaxel is limited to the injection method, and the surfactant in the paclitaxel formulation could cause severe side effects, including hair loss, muscle pain, serious allergic reaction, neurotoxicity, and nephrotoxicity. ${ }^{4,5}$

In the present study, we designed orally deliverable paclitaxel hybrid nanomicelles using the hypothesis that functionalized nanomedicine could be orally administered to treat breast cancer. Paclitaxel was formulated into hybrid micelles prepared with the polymer soluplus, $d-\alpha$-tocopheryl polyethyleneglycol 1000 succinate $\left(\mathrm{TPGS}_{1000}\right)$, and dequalinium (DQA).

Soluplus is an amphiphilic polyvinyl caprolactampolyvinyl acetate-polyethylene glycol graft copolymer and has solubilization potential for water-insoluble drugs. ${ }^{6,7}$ Micelles formulated with soluplus have a low critical micelle concentration value (about $10^{-8} \mathrm{M}$ ) and small in size $(\sim 65 \mathrm{~nm}) .^{7}$ In the molecular structure, soluplus has a hydrophilic polyethylene glycol backbone and several hydrophobic vinylcaprolactam/vinyl acetate side chains. Its hydrophobic carbonyl group can form hydrogen bonds with the hydroxyl groups of drug molecules, thus increasing the drug loading (DL) capacity and the stability of the micelles.

TPGS $_{1000}$ is a nonionic surfactant that has been used in pharmaceutical dosage forms after its approval by the US Food and Drug Administration (FDA) as a safe pharmaceutical adjuvant. It can increase drug solubility, enhance drug encapsulation efficiency (EE), ${ }^{8}$ and prolong the duration of the drug in the blood. Moreover, TPGS ${ }_{1000}$ could improve the oral bioavailability of anticancer drugs and inhibit drug efflux by ATP-binding cassette transporter (ABC transporters) overexpressing cells, such as drug-resistant cancer cells and gastrointestinal tract cells..$^{9,10}$ Therefore, TPGS ${ }_{1000}$-containing nanomicelles could successfully promote the oral absorption of anticancer drugs. ${ }^{11}$

DQA, 1,1'-(1,10-decanediyl) bis-(4-amino-2-methyl quinolinium), is an amphipathic cationic compound that is usually used as an antiseptic and disinfectant for wound dressings and mouth infections. Recent research indicated that DQA could selectively accumulate in mitochondria, driven by the transmembrane electric potential. ${ }^{12,13}$ Incorporation of cationic DQA in hybrid micelles might enhance the electrostatic interaction of the hybrid micelles with the negatively charged sialic acid groups in the intestinal mucus and with the negatively charged cancer cell membrane, thereby promoting intestinal absorption of the hybrid micelles and the subsequent cellular uptake by cancer cells.

The objectives of the present study were to develop orally deliverable paclitaxel hybrid nanomicelles, to investigate their anticancer efficacy in resistant breast cancer-bearing animals by oral administration, and to reveal their mechanism of action.

\section{Materials and methods Materials}

Soluplus was kindly provided by BASF Auxiliary Chem. Co., Ltd. (Shanghai, China). TPGS ${ }_{1000}$ was purchased from Sigma-Aldrich Co. (St Louis Co., MO, USA). DQA was obtained from Hangzhou Sanhe Chemicals, Co., Ltd. (Hangzhou, China). Paclitaxel was purchased from Nanjing Tianzun Zezhong Chemicals, Co., Ltd. (Nanjing, China). Coumarin and rhodamine 123 were purchased from SigmaAldrich Co. Other chemical reagents were obtained from Beijing Chemical Reagents (Beijing, China).

\section{Preparation of paclitaxel hybrid nanomicelles}

Paclitaxel hybrid nanomicelles were prepared via the following procedure. Briefly, soluplus, TPGS ${ }_{1000}$, and DQA (1/0.8/0.4 molar ratio) were used as micelle materials. Materials and paclitaxel (materials: $\operatorname{drug}=20: 1$, w/w) were dissolved in methanol in a pear-shaped flask. The methanol was then evaporated to form a thin film using a vacuum rotary evaporator. The thin film was hydrated with deionized water, followed by moderate stirring for $2 \mathrm{~h}$. The paclitaxel hybrid nanomicelles were obtained by filtration of the micelle suspensions through a $0.22 \mu \mathrm{m}$ polycarbonate membrane. Paclitaxel nanomicelles were prepared using the same protocol as that for the paclitaxel hybrid nanomicelles except without adding DQA and TPGS ${ }_{1000}$.

Coumarin hybrid nanomicelles and rhodamine 123 hybrid nanomicelles were prepared similarly as fluorescent probes.

\section{Characterization of the nanomicelles}

The mean particle size, polydisperisty index (PDI), and zeta potential of the various nanomicelles were estimated using a Nano Series Zen 4003 Zeta sizer (Malvern Instruments Ltd., Malvern, UK). The morphology of the paclitaxel hybrid nanomicelles was observed using transmission electron microscopy (TEM; Tecnai G2 20ST, FEI Co., Ltd., Tokyo, Japan).

The DL and EEs were investigated using a high performance liquid chromatography (HPLC) method (Agilent Technologies Inc., Santa Clara, CA, USA). All experiments were performed three times. The DL and EE were evaluated using the following formula: DL $(\%)=\left(\mathrm{W}_{\mathrm{i}} / \mathrm{W}_{\mathrm{PMs}}\right) \times 100 \%$, 
EE $(\%)=\left(\mathrm{W}_{\mathrm{i}} / \mathrm{W}_{\text {total }}\right) \times 100 \%$, where $\mathrm{W}_{\mathrm{i}}$ is the amount of encapsulated paclitaxel in the nanomicelles, $\mathrm{W}_{\mathrm{PMs}}$ is the total amount of the encapsulated paclitaxel and nanocarriers, and $\mathrm{W}_{\text {total }}$ is the total amount of paclitaxel.

The in vitro release of paclitaxel from the paclitaxel hybrid nanomicelles was assessed by the dialysis bag method. Briefly, $1 \mathrm{~mL}$ of nanomicelles containing $60 \mu \mathrm{g}$ of paclitaxel was added into a dialysis bag (molecular weight cut off=12-14 kDa; Greenbird Inc., Shanghai, China), and dialyzed in $40.0 \mathrm{~mL}$ of simulated gastric fluid (SGF, $0.1 \mathrm{M} \mathrm{HCl}$ solution, $\mathrm{pH} 1.2$ ) for $2 \mathrm{~h}$ with 100 revolutions per minute at $37^{\circ} \mathrm{C} \pm 0.5^{\circ} \mathrm{C}$. This was followed by dialyzing in $40.0 \mathrm{~mL}$ of simulated intestinal fluid (SIF, phosphate buffered saline [PBS] containing $137 \mathrm{mM} \mathrm{NaCl}, 2.7 \mathrm{mM}$ $\mathrm{KCl}, 8 \mathrm{mM} \mathrm{Na}_{2} \mathrm{HPO}_{4}$, and $2 \mathrm{mM} \mathrm{KH}_{2} \mathrm{PO}_{4}, \mathrm{PBS} \mathrm{pH}$ 7.4) for $48 \mathrm{~h}$ under the same conditions. A $0.5 \mathrm{~mL}$ volume of release solution was sampled at $0.5,1,2,4,8,12,24$, and $48 \mathrm{~h}$, while an equal volume of corresponding fresh release medium was added immediately. One milliliter of paclitaxel solution was used as a control. The paclitaxel solution was prepared by diluting a paclitaxel DMSO solution with distilled water. The sample was determined by HPLC as mentioned earlier. Each test was repeated in triplicate.

\section{Cell culture}

Human MCF-7 breast cancer cells were provided by the Institute of Materia Medica (Chinese Academy of Medical Sciences and Peking Union Medical College, Beijing, China) and the MCF-7/Adr drug-resistant breast cancer cells were provided by the Institute of Hematology and Blood Diseases Hospital (Chinese Academy of Medical Sciences and Peking Union Medical College). Cells were cultured in Roswell Park Memorial Institute 1640 medium (Macgene Biotech Co., Ltd, Beijing, China) containing 10\% heat-inactivated fetal bovine serum (Macgene Biotech). To maintain the drug resistance of MCF-7/Adr cells, MCF-7/Adr cells were cultured in the presence of $2 \mu \mathrm{M}$ doxorubicin and passaged for 1 week in a drug-free medium before the test. The cells were incubated at $37^{\circ} \mathrm{C}$ in a humidified environment containing a $5 \% \mathrm{CO}_{2}$ atmosphere.

\section{MCF-7/Adr cellular uptake}

To evaluate MCF-7/Adr cellular uptake qualitatively, MCF-7/Adr cells were seeded into chambered coverslips at a density of $3 \times 10^{5}$ cells/well under $5 \% \mathrm{CO}_{2}$ at $37^{\circ} \mathrm{C}$ for 24 h. Free rhodamine 123, rhodamine 123 nanomicelles, and rhodamine 123 hybrid nanomicelles were applied to the chambered coverslips for $4 \mathrm{~h}$. The final concentration of rhodamine 123 was $10 \mu \mathrm{M}$. The culture medium was used as a blank control. Cell culture medium was removed after incubation, and the cells were washed three times with PBS. The cell nuclei were stained with Hoechst $333342(5 \mu \mathrm{g} / \mathrm{mL})$ for $20 \mathrm{~min}$ and then washed with PBS for three times. Finally, the cells were analyzed using a laser scanning confocal microscope (Leica SP2; Leica Microsystems, Wetzlar, Germany) to observe the images of rhodamine 123 uptake by the MCF-7/Adr cells (excitation wavelength $=488 \mathrm{~nm}$, emission wavelength $=560 \mathrm{~nm}$ ).

To evaluate MCF-7/Adr cellular uptake quantitatively, MCF-7/Adr cells were seeded into six-well culture plates at a density of $3 \times 10^{5}$ cells/well under $5 \% \mathrm{CO}_{2}$ at $37^{\circ} \mathrm{C}$ for $24 \mathrm{~h}$. Free rhodamine 123, rhodamine 123 nanomicelles, and rhodamine 123 hybrid nanomicelles were applied to the six-well culture plates for $3 \mathrm{~h}$. The final concentration of rhodamine 123 was $10 \mu \mathrm{M}$. The culture medium was used as a blank control. The cells were washed for three times with PBS ( $\mathrm{pH} 7.4$ ), fixed with $4 \%$ paraformaldehyde $(\mathrm{v} / \mathrm{v})$ for $15 \mathrm{~min}$ under $5 \% \mathrm{CO}_{2}$ at $37^{\circ} \mathrm{C}$, trypsinized with $0.25 \%$ trypsinase, and collected. The harvested cells were subjected to FACScan flow cytometry to measure the fluorescence intensity of rhodamine 123 to assess the quantity of cellular uptake (excitation wavelength $=488 \mathrm{~nm}$, emission wavelength $=560 \mathrm{~nm}$ ).

\section{Targeting the mitochondria of MCF-7/ Adr cells}

The mitochondria-targeting feature of the paclitaxel hybrid nanomicelles was evaluated using a confocal laser scanning fluorescent microscopy for MCF-7/Adr cells. Coumarin was applied as the fluorescent probe. Briefly, MCF-7/Adr cells were seeded into chambered coverslips at a density of $3 \times 10^{5}$ cells/well and cultured for $24 \mathrm{~h}$ under $5 \% \mathrm{CO}_{2}$ at $37^{\circ} \mathrm{C}$. Free coumarin, coumarin nanomicelles, and coumarin hybrid nanomicelles were added to the wells, respectively. The final concentration of coumarin was $1.0 \mu \mathrm{M}$. After incubation for 4 h, cells were washed with PBS ( $\mathrm{pH} 7.4$ ) three times. The mitochondria of cells were then stained with $200 \mathrm{nM}$ Mito Tracker Deep Red FM (Thermo Fisher Scientific, Waltham, $\mathrm{MA}$, USA) for $30 \mathrm{~min}$ under $5 \% \mathrm{CO}_{2}$ at $37^{\circ} \mathrm{C}$, and cells were washed with PBS (pH 7.4) for three times. The cell nuclei were stained with Hoechst $333342(5 \mu \mathrm{g} / \mathrm{mL})$ for $30 \mathrm{~min}$. The cells were then washed with PBS ( $\mathrm{pH}$ 7.4) twice and observed under a laser scanning confocal microscope. Composite images were created by overlapping the images from the individual channels.

\section{In vitro cytotoxicity}

To assess the growth inhibition of different paclitaxel formulations on the MCF-7 or MCF-7/Adr cells, cells 
were seeded in 96-well culture plates at a density of $5 \times 10^{3}$ cells/well and grown for $24 \mathrm{~h}$ under $5 \% \mathrm{CO}_{2}$ at $37^{\circ} \mathrm{C}$. Various concentrations of the different formulations were separately added into the wells, consisting of free paclitaxel, paclitaxel nanomicelles, and paclitaxel hybrid nanomicelles. The final concentration of paclitaxel ranged from 0 to $10 \mu \mathrm{M}$. The culture medium was used as a blank control. After $48 \mathrm{~h}$, cell viability was estimated on the base of the absorbance at $540 \mathrm{~nm}$ on a microplate reader (Bio-Rad model 680; Bio-Rad Laboratories, Inc., Hercules, CA, USA) using the sulforhodamine B (SRB) staining assay. ${ }^{14}$ The following formula was used to calculate the survival rate: survival rate $(\%)=\left(A_{540 \mathrm{~nm}}\right.$ for the treated cells $/ A_{540 \mathrm{~nm}}$ for the control cells) $\times 100 \%$, where $\mathrm{A}_{540 \mathrm{~nm}}$ is the absorbance value. Dose-effect curves were constructed. The tests were performed in triplicate.

\section{Apoptosis-inducing effect}

Apoptosis was evaluated using an Annexin V647/ 7-Aminoactinomycin D (7AAD) staining apoptosis detection kit (Nanjing Keygen Biotech. Co., Ltd., Nanjing, China) by flow cytometry. Briefly, MCF-7/Adr cells were seeded into six-well culture plates at a density of $3 \times 10^{5}$ cells/well and cultured for $24 \mathrm{~h}$ under $5 \% \mathrm{CO}_{2}$ at $37^{\circ} \mathrm{C}$. The cells were then incubated with free paclitaxel, paclitaxel nanomicelles, and paclitaxel hybrid nanomicelles for $12 \mathrm{~h}$, respectively. The final concentration of paclitaxel was $10 \mu \mathrm{M}$. The culture medium was used as a blank control. After incubation, the cells were washed twice with PBS ( $\mathrm{pH} 7.4)$, collected, and resuspended in $0.3 \mathrm{~mL}$ binding buffer provided in the detection kit. Cells were incubated with $5 \mu \mathrm{L}$ Annexin V647 for $15 \mathrm{~min}$ in the dark at room temperature and then with $5 \mu \mathrm{L}$ $7 \mathrm{AAD}$ for $10 \mathrm{~min}$. The cells were analyzed by flow cytometry to assess the apoptosis-inducing effect.

\section{Apoptosis-inducing mechanism}

Apoptosis-inducing signaling pathways were studied in drug-resistant MCF-7/Adr breast cancer cells after treatment with different formulations by a high-content screening system. MCF-7/Adr cells were seeded into 96-well culture plates at a density of $3 \times 10^{5}$ cells/well and cultured for $24 \mathrm{~h}$ under $5 \% \mathrm{CO}_{2}$ at $37^{\circ} \mathrm{C}$. The cells were incubated with blank culture medium, free paclitaxel, paclitaxel nanomicelles, and paclitaxel hybrid nanomicelles for $6 \mathrm{~h}$ under the same conditions. The final concentration of paclitaxel was $10 \mu \mathrm{M}$. The cells were fixed with 4\% paraformaldehyde for $15 \mathrm{~min}$ under $5 \% \mathrm{CO}_{2}$ at $37^{\circ} \mathrm{C}$ and penetrated with $0.5 \%$ Triton $\mathrm{X}-100$ and $0.3 \mathrm{M}$ glycine for $15 \mathrm{~min}$. After washing with PBS ( $\mathrm{pH}$ 7.4) for three times, the cells were incubated with
$5 \%$ goat serum for $2 \mathrm{~h}$ at room temperature. Subsequently, the cells were incubated with primary antibodies recognizing caspase 3, caspase 9, cytochrome C, Bax, Bcl-2, and Mcl-1 (Sangon Biotech Co., Ltd., Shanghai, China), respectively, for $6 \mathrm{~h}$ at $4^{\circ} \mathrm{C}$, and then washed with PBS for three times. Afterward, the cells were incubated with relevant secondary antibodies (Alexa Fluor 647-labeled Goat Anti-Rabbit $\operatorname{IgG}[\mathrm{H}+\mathrm{L}]$ and Alexa Fluor 647-labeled Goat Anti-mouse $\operatorname{IgG}[\mathrm{H}+\mathrm{L}])$ for $2 \mathrm{~h}$ at room temperature and then stained with Hoechst $333342(5 \mu \mathrm{g} / \mathrm{mL})$ for $30 \mathrm{~min}$. Both primary and secondary antibodies were diluted according to the manufacturer's instructions. Finally, the cells were washed with PBS ( $\mathrm{pH} 7.4$ ) twice and preserved in $50 \mu \mathrm{L}$ of PBS. The apoptotic proteins were estimated with a high-content screening system (Perkin Elmer, Inc., Waltham, MA, USA) and quantified using the Columbus system.

\section{Anticancer efficacy in mice by oral administration}

To investigate the antitumor efficacy in vivo, female BALB/c nude mice (initially weighing 16-18 g) were purchased from the Peking University Health Science Center. All animal experiments were performed in accordance with the principles of the Guide for the Care and Use of Laboratory Animals and were approved by the Institutional Animal Care and Use Committee of Peking University. Tumor models were established by injecting MCF-7/Adr cells $\left(1 \times 10^{7}\right.$ cells/mice $)$ subcutaneously into the right flanks of the nude mice. The volume of tumors in mice was observed and recorded. When the volume of tumors reached $\sim 150 \mathrm{~mm}^{3}$, mice were sorted into the following experimental groups ( $n=6$ in each group) randomly: physiological saline (orally [po]), taxol (10 mg/kg, po), taxol (10 mg/kg, intravenous [iv]), and paclitaxel hybrid nanomicelles $(10 \mathrm{mg} / \mathrm{kg}$, po), which were administered to the mice on the 18th, 20th, $22 \mathrm{nd}, 24 \mathrm{th}, 28 \mathrm{th}$, and 30 th day postinoculation. The tumor volume and body weight of the mice were then measured every 2 days. Tumor volumes (V) were calculated by the following formula: $\mathrm{V}=\left(\mathrm{L} \times \mathrm{W}^{2}\right) / 2\left(\mathrm{~mm}^{3}\right)$, where $\mathrm{L}$ and $\mathrm{W}$ represent the length and width, respectively. The body weight of mice was investigated during the course of experiment to assess possible toxic effects of the formulations. Mice were sacrificed on the 31 st day post-inoculation, and then tumor tissues were removed and weighed immediately.

\section{Statistical analysis}

Data are represented as the mean $\pm \mathrm{SD}$. One-way analysis of variance was used to determine the significance among 
the groups, after which post hoc tests with the Bonferroni correction were used for comparison between individual groups. A value of $P<0.05$ was considered statistically significant.

\section{Results}

\section{Preparation and characterization of the nanomicelles}

The preparation and characterization of the nanomicelles included average particle sizes, PDI, zeta potential, DL capacity, and EE (Table 1). Schematic representations of the paclitaxel nanomicelles and paclitaxel hybrid nanomicelles are shown in Figure 1A. The results demonstrated that the average particle size of the paclitaxel hybrid nanomicelles was $\sim 65 \mathrm{~nm}$, with a narrow size distribution $(\mathrm{PDI}<0.20)$. The addition of $\mathrm{TPGS}_{1000}$ and DQA had no effect on the particle size. To better describe the shape of the paclitaxel hybrid nanomicelles, their morphology was observed using TEM (Figure 1B). The paclitaxel hybrid nanomicelles were spherical, and their apparent size was similar to $\sim 65 \mathrm{~nm}$. The zeta potential values of paclitaxel nanomicelles and paclitaxel hybrid nanomicelles were $-14.6 \pm 0.77 \mathrm{mV}$ and $-0.679 \pm 0.15 \mathrm{mV}$, respectively. The DL efficiencies of the paclitaxel nanomicelles and paclitaxel hybrid nanomicelles were $5.57 \% \pm 0.15 \%$ and $5.05 \% \pm 0.18 \%$, respectively. The EEs of both the nanomicelles were above $85 \%$.

The in vitro release rates of nanomicelles were observed in the SGF for $2 \mathrm{~h}$ and in the SIF for $48 \mathrm{~h}$, successively. The accumulative release of paclitaxel from free paclitaxel, paclitaxel nanomicelles, and paclitaxel hybrid nanomicelles in SGF was about 20.29\%, 9.31\%, and $15.15 \%$ at $2 \mathrm{~h}$, while they were $26.99 \% \pm 3.68 \%, 37.43 \% \pm 2.65 \%$, and $39.74 \% \pm 3.69 \%$ at $48 \mathrm{~h}$, respectively (Figure $1 \mathrm{C}$ ). The results indicated that the paclitaxel leakage percentage from the paclitaxel nanomicelles or paclitaxel hybrid nanomicelles

Table I Characterization of paclitaxel hybrid nanomicelles

\begin{tabular}{llll}
\hline Measurements & $\begin{array}{l}\text { Blank hybrid } \\
\text { nanomicelles }\end{array}$ & $\begin{array}{l}\text { Paclitaxel } \\
\text { nanomicelles }\end{array}$ & $\begin{array}{l}\text { Paclitaxel } \\
\text { hybrid } \\
\text { nanomicelles }\end{array}$ \\
\hline Particle size (nm) & $61.05 \pm 0.14$ & $63.4 I \pm 0.58$ & $64.03 \pm 0.77$ \\
Polydisperisty index & $0.11 \pm 0.02$ & $0.14 \pm 0.04$ & $0.18 \pm 0.04$ \\
Zeta potential (mV) & $-0.8 \pm 0.64$ & $-14.60 \pm 0.77$ & $-0.68 \pm 0.15$ \\
$\begin{array}{l}\text { Encapsulation } \\
\text { efficiency (\%) }\end{array}$ & - & $96.21 \pm 0.48$ & $86.40 \pm 0.93$ \\
$\begin{array}{l}\text { Drug loading } \\
\text { efficiency (\%) }\end{array}$ & - & $5.57 \pm 0.15$ & $5.05 \pm 0.18$ \\
\hline
\end{tabular}

Note: Data are presented as mean \pm SD. was less than $40 \%$ over $48 \mathrm{~h}$ in the simulated gastrointestinal tract.

\section{MCF-7/Adr cellular uptake}

The cellular uptake efficiency by MCF-7/Adr cells after treatment with free rhodamine 123, rhodamine 123 nanomicelles, or rhodamine 123 hybrid nanomicelles was assessed by confocal laser scanning microscopy (Figure 2A). Green fluorescence indicated that rhodamine 123 was internalized by the cells, while blue fluorescence indicated that Hoechst 333342 was located in the cell nuclei. The results demonstrated that free rhodamine 123 had the weakest fluorescence intensity in MCF-7/Adr cells, while rhodamine 123 hybrid nanomicelles exhibited the strongest fluorescence intensity.

The fluorescence intensity of rhodamine 123 was further quantitatively demonstrated by flow cytometry (Figure 2B and C). The results indicated that the mean fluorescence intensities after treatment with culture medium, free rhodamine 123, rhodamine 123 nanomicelles, and rhodamine 123 hybrid nanomicelles for $4 \mathrm{~h}$ were $552.90 \pm 8.68,9,737.43 \pm 184.35$, $19,441.83 \pm 1,058.27$, and 269,311.43 $\pm 9,848.60$, respectively. The results were consistent with the qualitative results for cellular uptake observed using confocal laser scanning microscopy.

\section{Targeting the mitochondria of MCF-7/ Adr cells}

The targeting effects of coumarin hybrid nanomicelles in MCF-7/Adr cells were evaluated by confocal laser scanning microscopy (Figure 3). Mitochondria in the cells were stained with red fluorescence by Mito Tracker Deep Red FM, and free coumarin acted as a green fluorescent probe to indicate the subcellular localization of the drug. A bright yellow fluorescence indicated overlapping red and green fluorescence, indicating the co-localization of the drug with the mitochondria. The results showed that coumarin hybrid nanomicelles were accumulated selectively into the mitochondria, while coumarin nanomicelles and free coumarin did not localize in the mitochondria.

\section{In vitro cytotoxicity}

Growth inhibitory effects of various formulations on MCF-7 and $\mathrm{MCF}-7 / \mathrm{Adr}$ cells were measured using an SRB assay (Figure 4). Blank hybrid nanomicelles showed neglectable cytotoxicity to MCF-7 and MCF-7/Adr cells. All formulations exhibited paclitaxel concentration-dependent cytotoxic effects on MCF-7 and on MCF-7/Adr cells. The dose required for $50 \%$ growth inhibition (IC50 value) for the 


\section{A1}

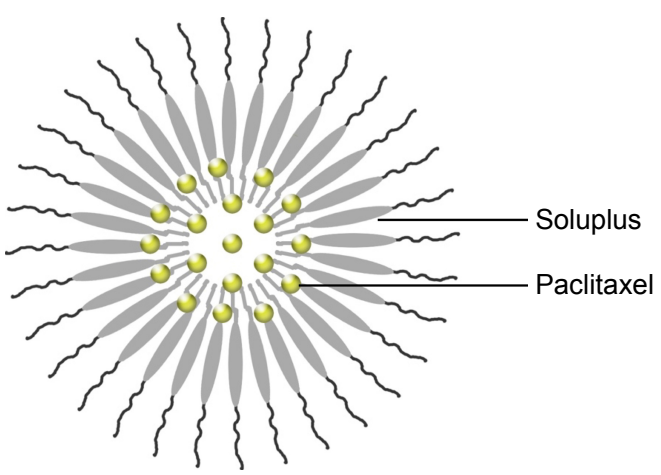

B

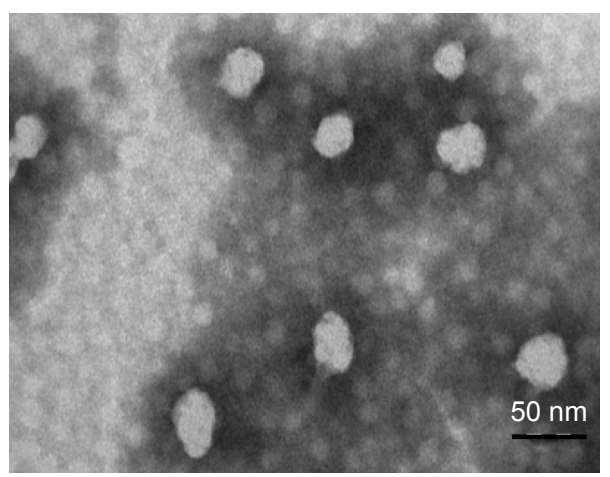

A2

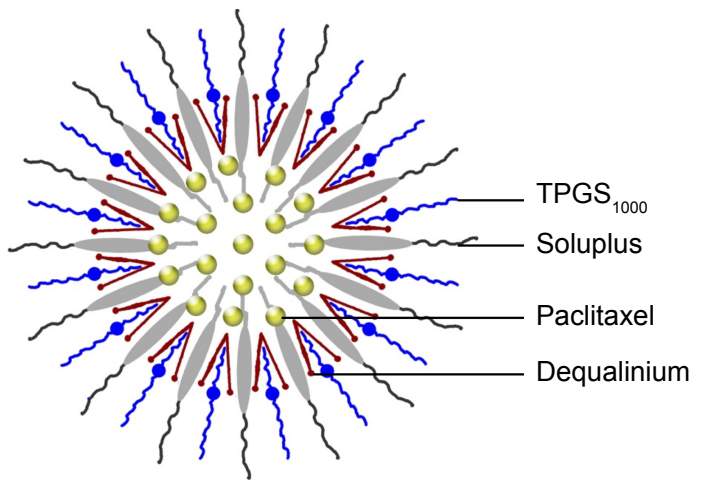

C

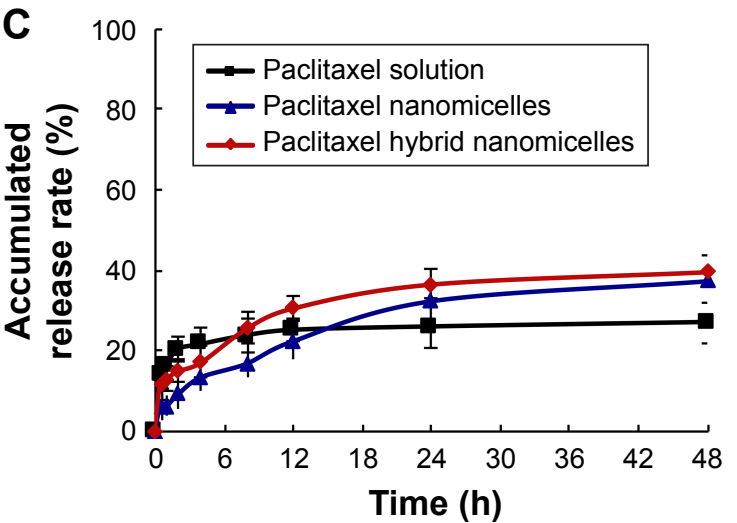

Figure I Characterization of paclitaxel hybrid nanomicelles.

Notes: (A) Schematic representations of paclitaxel nanomicelles (AI) and paclitaxel hybrid nanomicelles (A2). (B) Transmission electron microscopy image of paclitaxel hybrid nanomicelles, scale bar $=50 \mathrm{~nm}$. (C) Paclitaxel release rates (\%) of paclitaxel solution, paclitaxel nanomicelles, and paclitaxel hybrid nanomicelles in simulated gastric

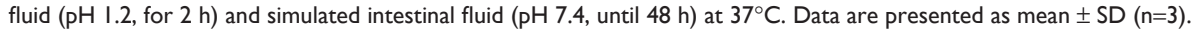

Abbreviation: TPGS ${ }_{1000}, d$ - $\alpha$-tocopheryl polyethyleneglycol 1000 succinate.

paclitaxel hybrid nanomicelles, paclitaxel nanomicelles, and free paclitaxel were $0.287 \mu \mathrm{M}, 0.3767 \mu \mathrm{M}$, and $0.8359 \mu \mathrm{M}$, respectively, for MCF-7 cells and $1.105 \mu \mathrm{M}, 9.949 \mu \mathrm{M}$, and $23.21 \mu \mathrm{M}$, respectively, for MCF-7/Adr cells. Free paclitaxel exhibited obvious cytotoxicity to MCF-7 cells but was less cytotoxic to MCF-7/Adr cells. Paclitaxel nanomicelles evidently improved the cytotoxicity of paclitaxel toward MCF-7/Adr cells. Moreover, paclitaxel hybrid nanomicelles showed stronger cytotoxicity to MCF-7/Adr cells compared with free paclitaxel or with paclitaxel nanomicelles. Briefly, the degree of cytotoxicity was paclitaxel hybrid nanomicelles $>$ paclitaxel nanomicelles $>$ free paclitaxel $>$ blank hybrid nanomicelles.

\section{Apoptosis-inducing effect}

Apoptosis-inducing effects of various formulations on MCF-7/Adr cells were evaluated by flow cytometry (Figure 5). The percentage of apoptosis in MCF-7/Adr cells after treatment with culture medium, free paclitaxel, paclitaxel nanomicelles, and paclitaxel hybrid nanomicelles was $0.88 \% \pm 0.52 \%, 1.76 \% \pm 0.74 \%, 8.54 \% \pm 1.25 \%$, and
$32.93 \% \pm 5.85 \%$, respectively. Paclitaxel hybrid nanomicelles showed the most evident apoptosis-inducing effect in MCF-7/Adr cells compared with paclitaxel nanomicelles or with free paclitaxel.

\section{Apoptosis-inducing mechanism}

The levels of apoptotic proteins and enzymes in MCF-7/ Adr cells after treatment with various formulations were measured using a high-content screening system (Figure 6). The results revealed that after treatment with culture medium, free paclitaxel, paclitaxel nanomicelles, and paclitaxel hybrid nanomicelles, the activities of cytochrome $\mathrm{C}$ were $1.00 \pm 0.03,1.05 \pm 0.05,1.08 \pm 0.05,1.19 \pm 0.03$; the activities of caspase 9 were $1.00 \pm 0.01,1.02 \pm 0.03,1.08 \pm 0.02,1.16 \pm 0.04$; the activities of caspase 3 were $1.00 \pm 0.01,1.03 \pm 0.03$, $1.06 \pm 0.03,1.19 \pm 0.02$; the activities of Bax were $1.00 \pm 0.17$, $1.07 \pm 0.06,1.11 \pm 0.03,1.25 \pm 0.06$; the activities of $\mathrm{Bcl}-2$ were $1.00 \pm 0.09,0.88 \pm 0.07,0.79 \pm 0.03,0.72 \pm 0.02$; and the activities of Mcl-1 were $1.00 \pm 0.06,0.91 \pm 0.06,0.86 \pm 0.04$, $0.79 \pm 0.02$, respectively. The results showed that paclitaxel hybrid nanomicelles could increase the activity of 
A Rhodamine 123
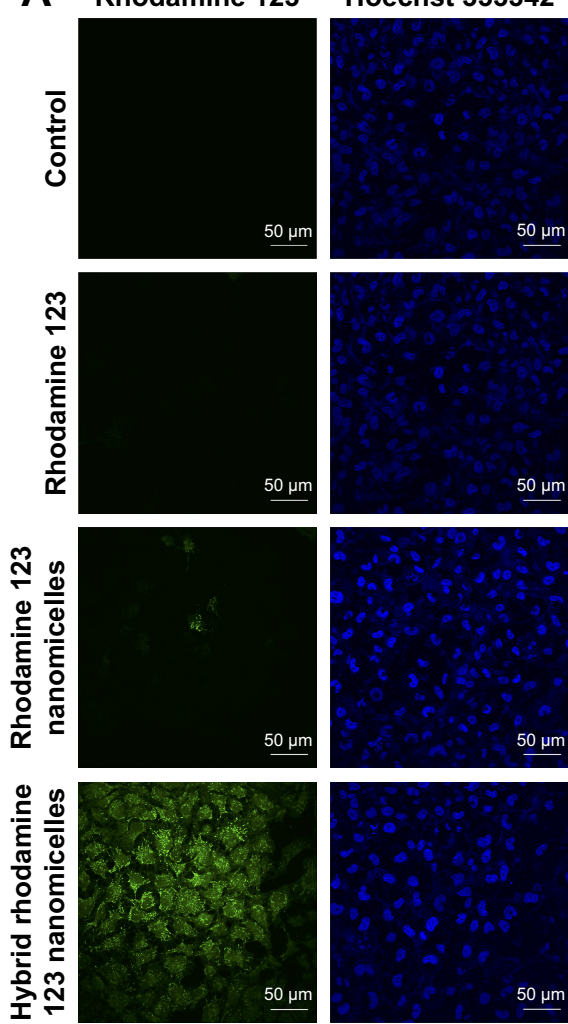

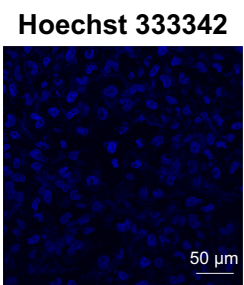

Combined
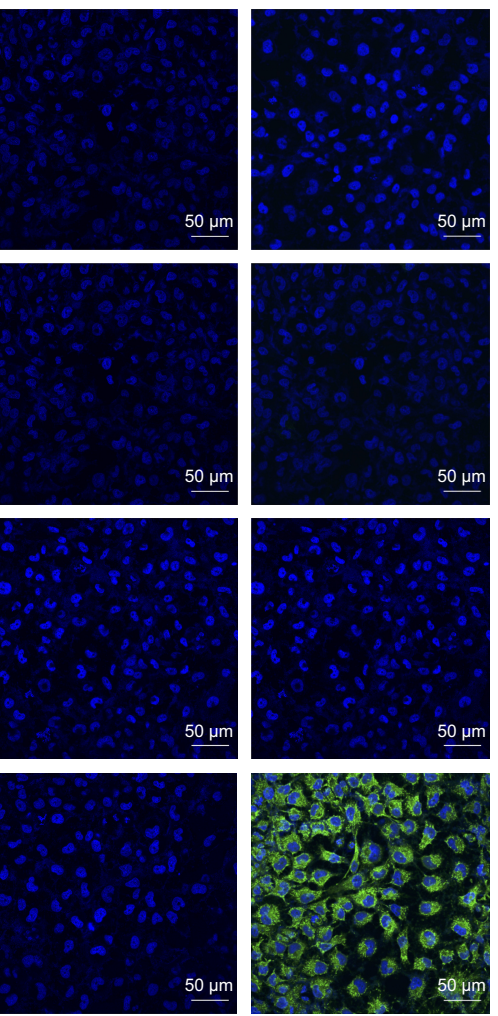

B
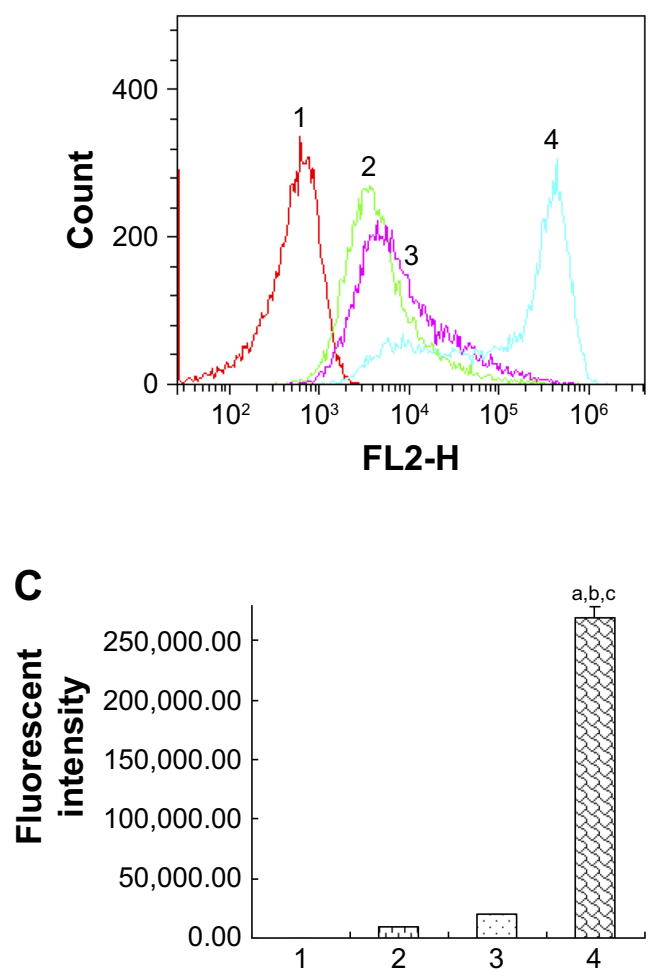

Figure 2 Intracellular uptake by MCF-7/Adr cells after treatment with various formulations.

Notes: (A) Laser scanning confocal fluorescence images of cells. Rhodamine 123 was used as a fluorescent indicator, while the nucleus was stained with Hoechst 333342. (B and C) Flow cytometry analysis of intracellular uptake by MCF-7/Adr cells: I, control; 2, rhodamine I23; 3, rhodamine I23 nanomicelles; 4 , rhodamine I23 hybrid nanomicelles. $P<0.05$; a, vs control; b, vs rhodamine 123; c, vs rhodamine 123 nanomicelles. Data are presented as mean $\pm S D$ ( $n=3$ ).

cytochrome C, caspase 9, caspase 3, and pro-apoptotic protein Bax but decreased the activity of anti-apoptotic protein Mcl-1 and anti-apoptotic protein Bcl-2.

\section{Anticancer efficacy in mice by oral administration}

Anticancer efficacy was indicated by the volume and weight of tumor tissue in MCF-7/Adr-bearing mice (Figure 7A and B). The rank of tumor volume or weight was paclitaxel hybrid nanomicelles (po) $\geq$ taxol (iv) $>$ taxol (po) $>$ control (po). The tumor inhibition rate of paclitaxel hybrid nanomicelles by oral administration $(87.45 \% \pm 12.15 \%$ at day 30) was similar to that of taxol by intravenous injection $(73.26 \% \pm 24.02 \%$ at day 30$)$.

The body weight changes of the tumor-bearing mice were recorded during the experiment (Figure 7C). The results showed that the body weight of the mice showed no evident change after oral administration of paclitaxel hybrid nanomicelles; however, the body weight showed a moderate reduction after intravenous injection of taxol.

\section{Discussion}

In this study, a nanostructure for oral drug delivery was developed for cancer therapy. The fabricated paclitaxel hybrid nanomicelles could be administrated orally, thus permitting chemotherapy at home and the avoidance of side effects, such as allergic reaction caused by the surfactant. The oral suitability of paclitaxel hybrid nanomicelles is derived from the nanostructured micelles and the action of the functional materials TPGS $_{1000}$ and DQA.

The constructed paclitaxel hybrid nanomicelles were characterized as having a nanosize (with a narrow distribution), high DL and EE, and a low drug leakage rate (Figure 1). The appropriate particle size (50-100 nm) of the nanomicelles could enhance oral absorbability by improving the transport across the gastrointestinal tract and absorption into the blood system. ${ }^{11,15,16}$ Furthermore, the PEGylated TPGS ${ }_{1000}$ allows the micelles to escape from the fast uptake by reticuloendothelial system, while the nanostructure improves the permeation and retention effect, thus effectively accumulating nanomicelles into the 

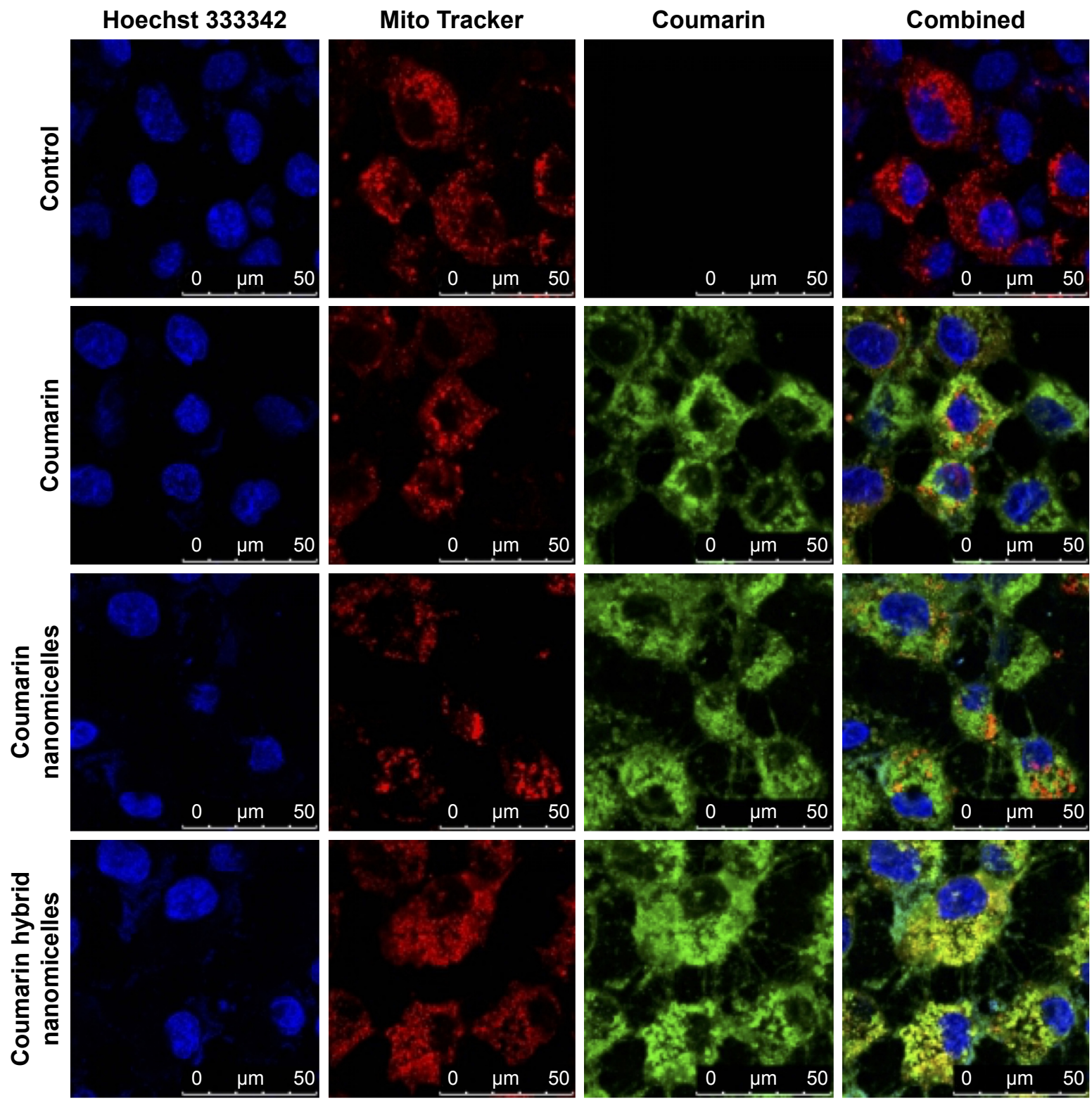

Figure 3 Co-localization of paclitaxel hybrid nanomicelles with mitochondria in MCF-7/Adr cells. After treatment with various formulations for 4 h, co-localization was observed by laser scanning confocal microscopy. Coumarin was used as the fluorescent probe.

tumor site. ${ }^{17}$ In addition, soluplus could form hydrogen bonds with paclitaxel, which improves the stability of the nanomicelles, enhances the DL and EE, and reduces drug leakage.

The cellular uptake evaluation revealed that the hybrid nanomicelles could be internalized more efficiently by drugresistant cancer cells (Figure 2). The enhanced cellular uptake of the hybrid nanomicelles could be attributed to TPGS ${ }_{1000}$, which inhibits drug efflux by the ABC transporters. ${ }^{18}$ Moreover, positively charged DQA could improve cellular uptake by adsorption onto the negatively charged cancer cell membrane. Further studies on the localization of the nanomicelles suggested that the hybrid nanomicelles could be specifically accumulated into mitochondria, leading to mitochondrial dysfunction (Figure 3). The co-localization of the hybrid nanomicelles with mitochondria resulted from the mitochondria targeting effect of DQA, driven by the transmembrane electric potential. ${ }^{19}$

According to the in vitro cytotoxicity assay, the blank hybrid nanomicelles exhibited lower cytotoxicity, indicating their safety as a nanocarrier (Figure 4). Paclitaxel hybrid nanomicelles had the strongest inhibitory effect on MCF-7 cells or MCF-7/Adr cells. In particular, the paclitaxel hybrid nanomicelles significantly improved the anticancer efficacy in MCF-7/Adr cells compared with paclitaxel nanomicelles or free paclitaxel, demonstrating that the paclitaxel hybrid 

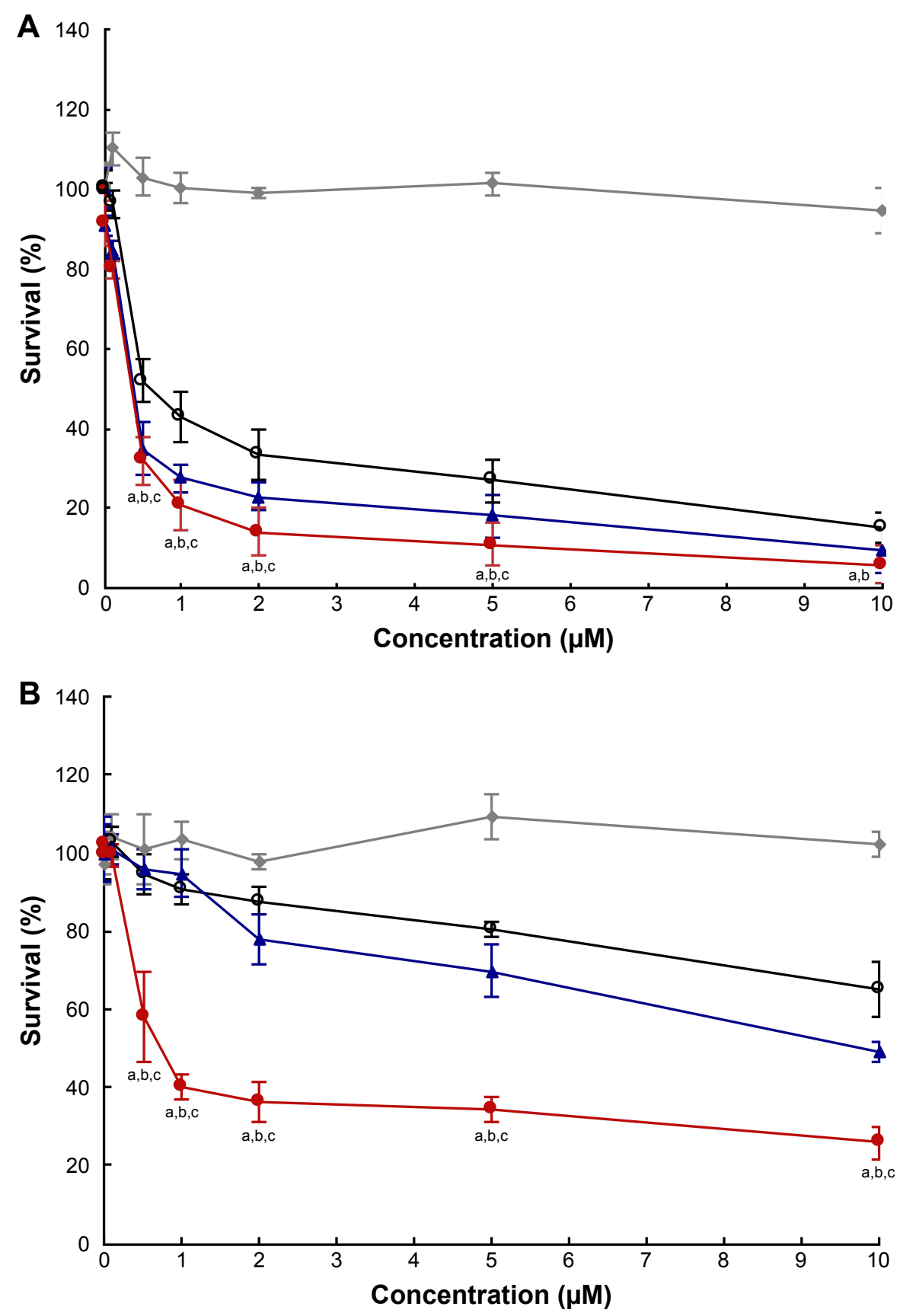

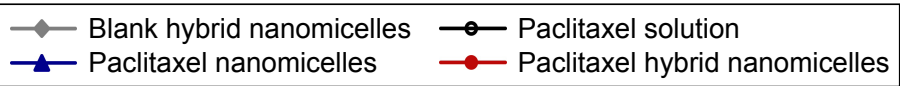

Figure 4 Survival rates of MCF-7 (A) or MCF-7/Adr (B) cells after treatment with various formulations. $P<0.05$; a, vs hybrid blank nanomicelles; b, vs paclitaxel solution; c, vs paclitaxel nanomicelles. Data are presented as mean \pm SD $(n=3)$.

nanomicelles could evidently circumvent drug resistance of the cancer cells. The mechanism can be explained by the following two aspects. On the one hand, TPGS 1000 is able to inhibit drug efflux by $\mathrm{ABC}$ transporters overexpressed on the membrane of resistant cancer cells. ${ }^{20,21}$ On the other hand, the mitochondria targeting effect induced by DQA increases apoptosis of the resistant cancer cells, as discussed in the following section.
The paclitaxel hybrid nanomicelles exhibited the strongest apoptosis-inducing effect on MCF-7/Adr cells among the formulations (Figure 5). The mechanistic investigation showed that the apoptosis induced by the paclitaxel hybrid nanomicelles is mediated by mitochondria-dependent signaling pathways (Figure 6). Paclitaxel hybrid nanomicelles co-locate with mitochondria, destroying the mitochondrial membrane and leading to the release of cytochrome $\mathrm{C}$ into 

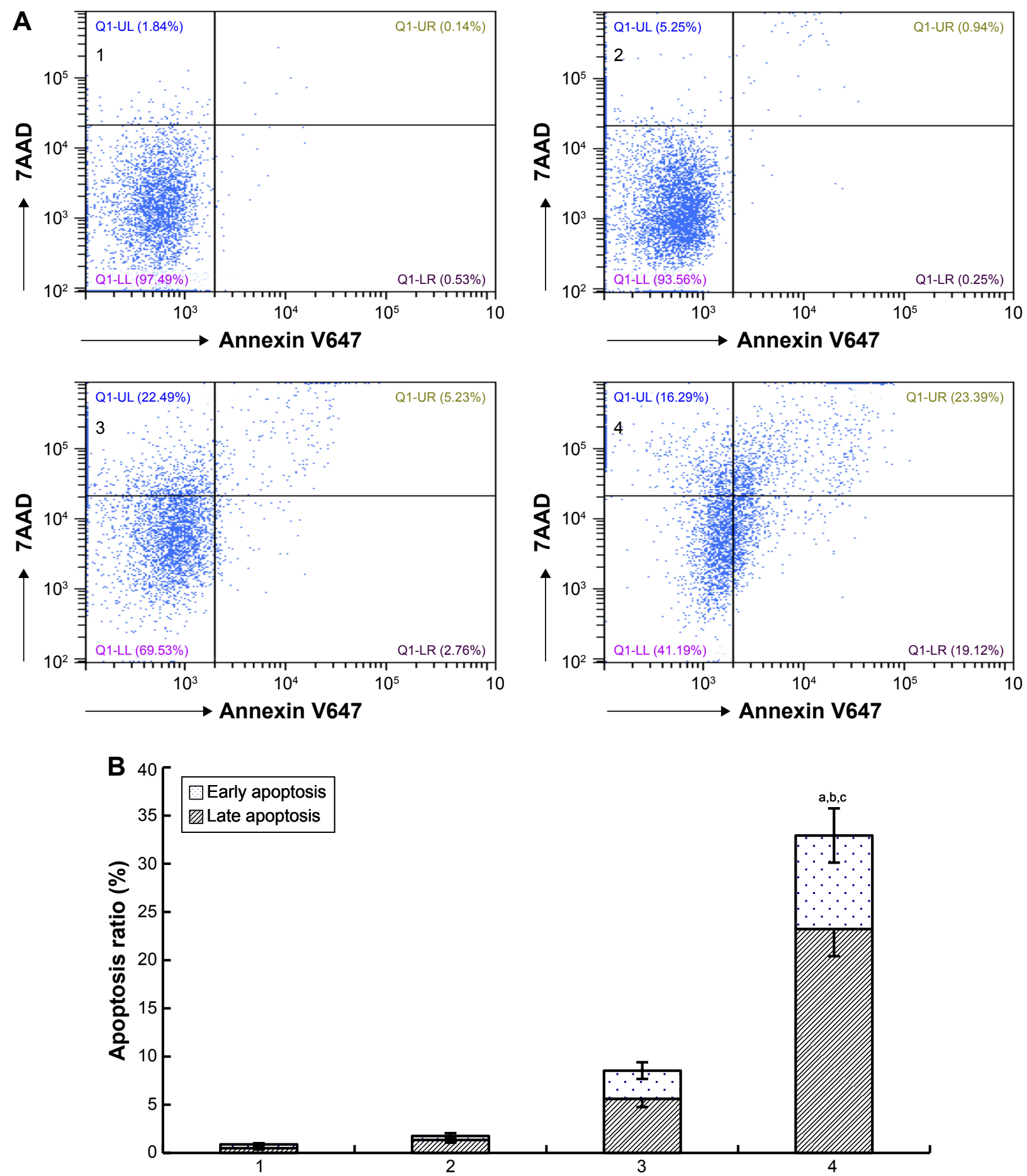

Figure 5 Induced apoptosis on MCF-7/Adr cells after treatment with various formulations.

Notes: (A,B) I, control; 2, paclitaxel solution; 3, paclitaxel nanomicelles; 4, paclitaxel hybrid nanomicelles. $\mathrm{P}<0.05$; a, vs control; b, vs paclitaxel solution; c, vs paclitaxel nanomicelles. Data are presented as mean $\pm S D(n=3)$.

Abbreviation: 7AAD, 7-Aminoactinomycin D.

the cytosol. ${ }^{22,23}$ Meanwhile, the paclitaxel hybrid nanomicelles decreased the levels of anti-apoptotic proteins Bcl-2 and Mcl-1 while upregulating the level of pro-apoptotic protein Bax, which triggers the increased permeability of the transmembrane pore (PT pore), thus facilitating the release of cytochrome $\mathrm{C}$. Consequently, the released cytochrome $\mathrm{C}$ further activates the upstream apoptotic enzyme caspase 9 and then the downstream effector caspase 3, finally inducing a cascade of apoptotic reactions..$^{24,25}$

Oral efficacy was demonstrated in a resistant cancer MCF-7/Adr-xenografted nude mouse model (Figure 7). The result showed that the effects of oral administration of 

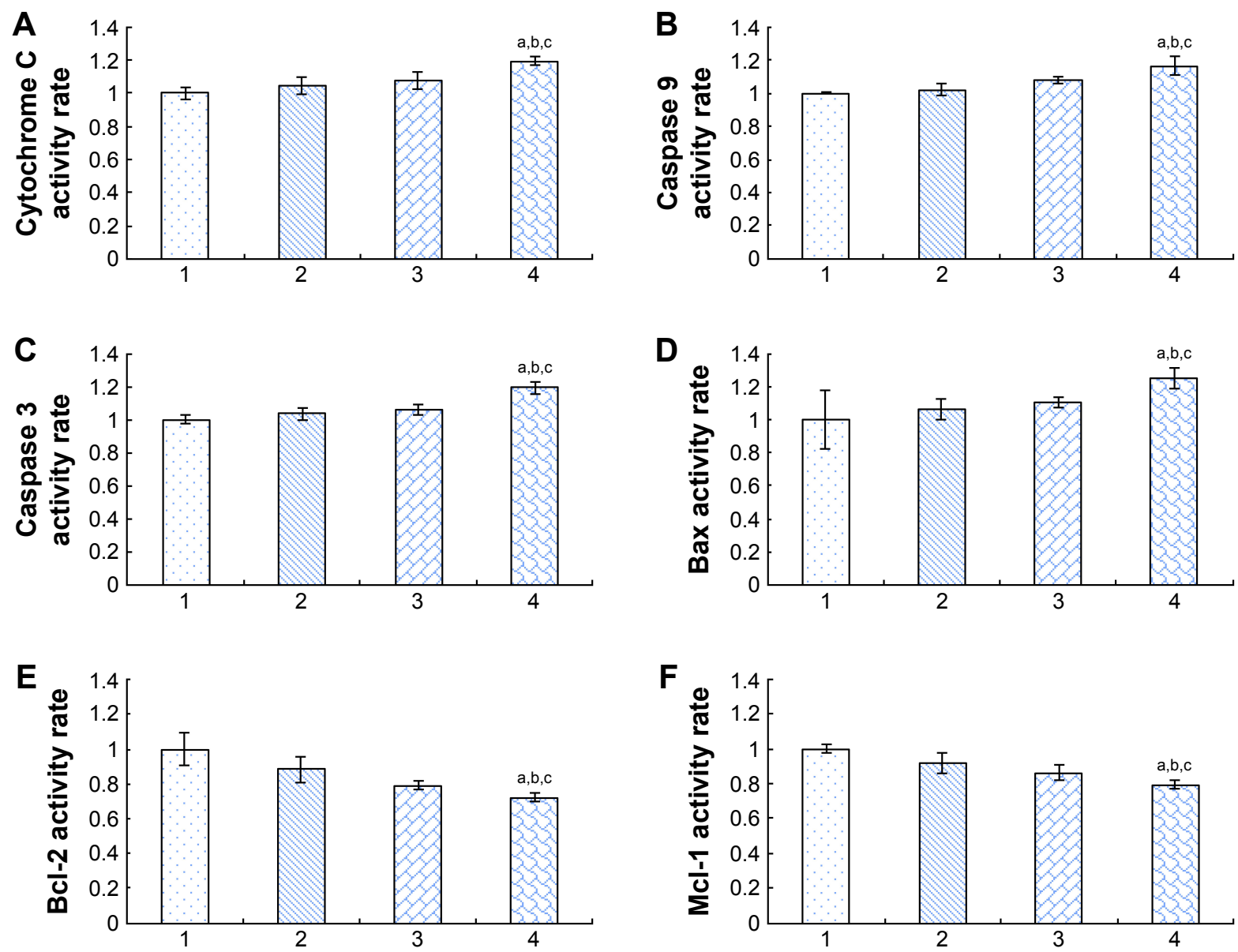

Figure 6 Activation of pro-apoptotic proteins and inhibition of anti-apoptotic proteins in MCF-7/Adr cells after treatment with various formulations

Notes: (A-F) I, control; 2, paclitaxel solution; 3, paclitaxel nanomicelles; 4, paclitaxel hybrid nanomicelles. $P<0.05$; a, vs control; b, vs paclitaxel solution; c, vs paclitaxel nanomicelles. Data are presented as mean \pm SD $(n=3)$.

paclitaxel hybrid nanomicelles were comparable to those of intravenous injection of taxol. In addition, the paclitaxel hybrid nanomicelles exhibited the potential to inhibit resistant breast cancer cells. Compared with the normal control, the paclitaxel hybrid nanomicelles did not cause any appreciable toxicity in the mice. Collectively, these results revealed the prospect of this formulation for further development.

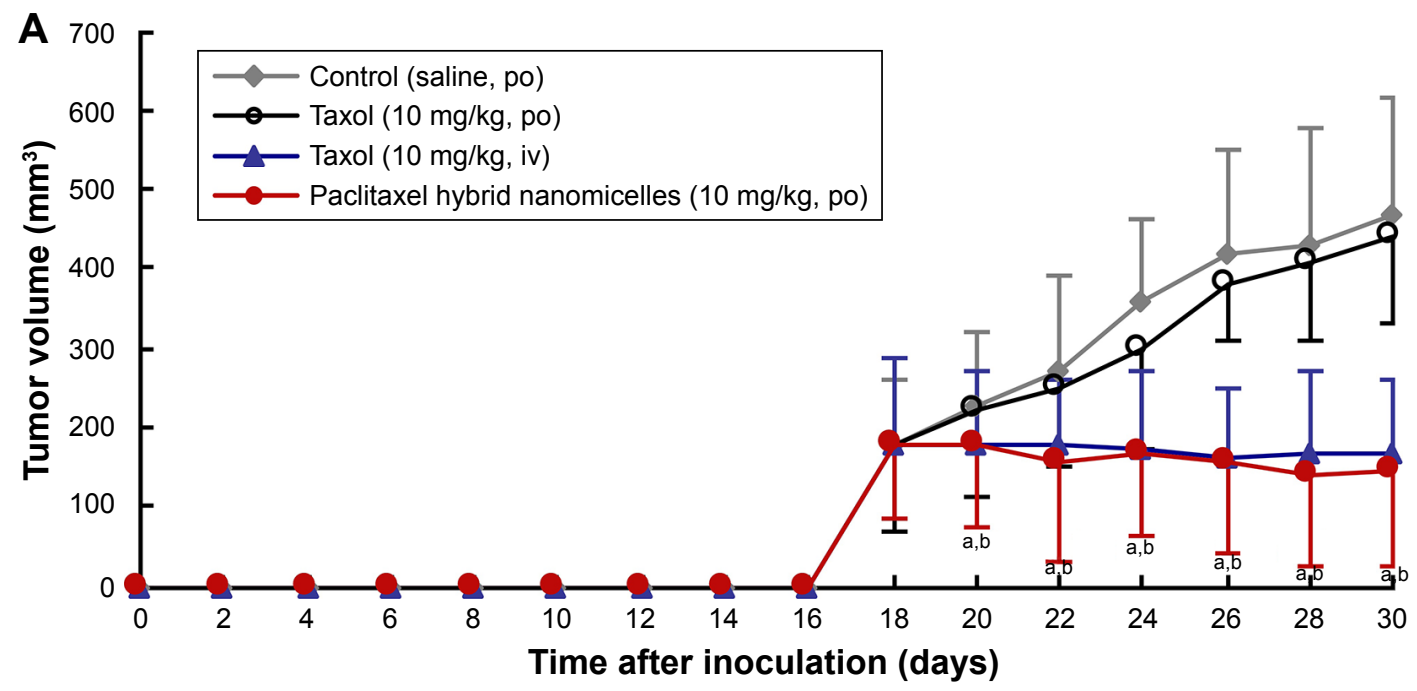

Figure 7 (Continued) 

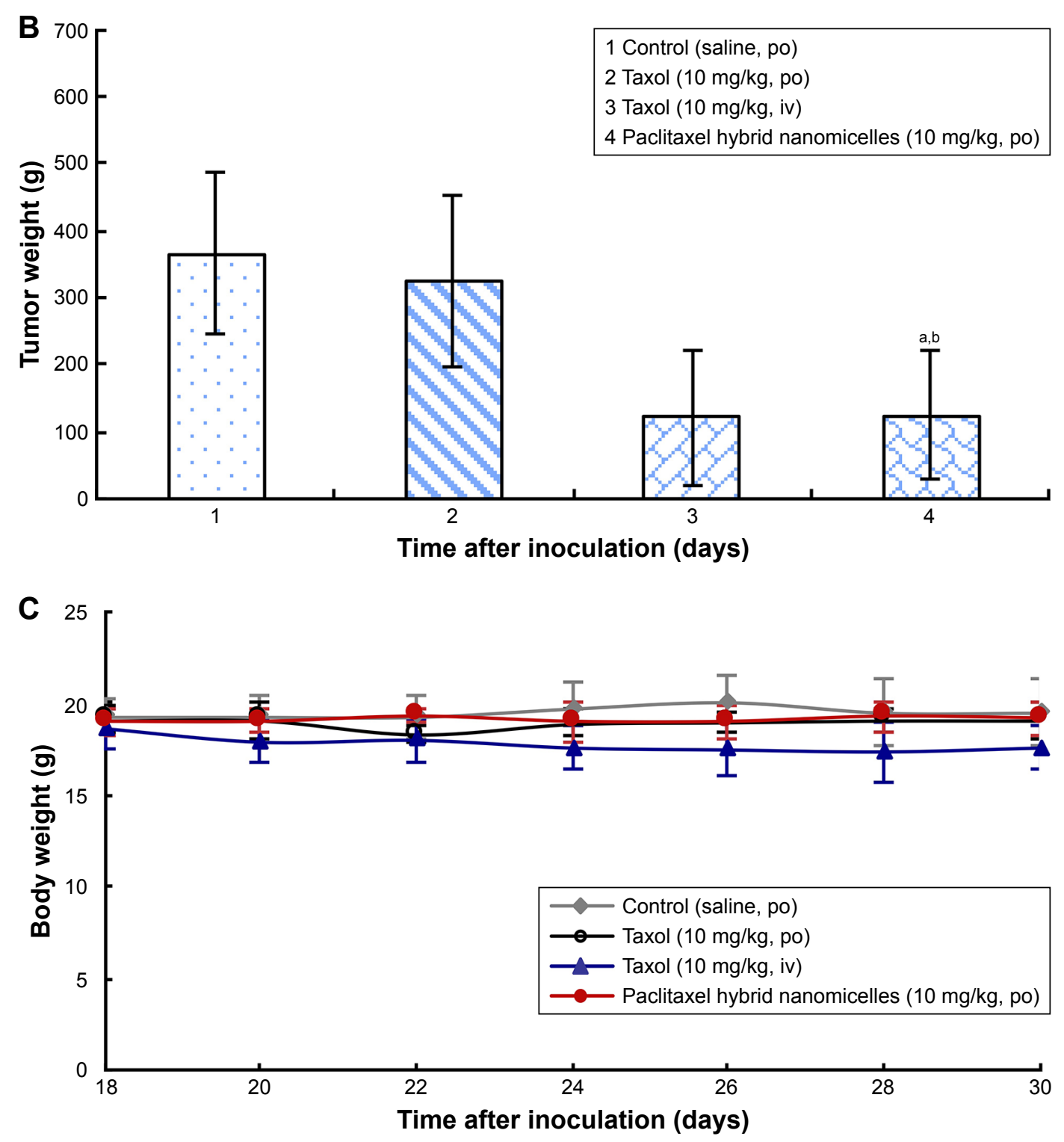

Figure 7 Antitumor efficacy by oral administration of paclitaxel hybrid nanomicelles in drug resistant breast cancer-bearing mice.

Notes: (A) Tumor volume changes in mice after administration; (B) tumor weight in mice after administration; (C) body weight changes of mice after administration. I, control (saline, po); 2, taxol (po); 3, taxol (iv); 4, hybrid paclitaxel nanomicelles (po). $P<0.05$; a, vs control (saline, po); b, vs taxol (po). Data are presented as mean \pm SD ( $=6$ ).

Abbreviations: po, orally; iv, intravenous.

In summary, the fabricated paclitaxel hybrid nanomicelles were $\sim 65 \mathrm{~nm}$ in size and exhibited enhanced cellular uptake and significant anticancer efficacy to treat resistant breast cancer cells. In addition, they effectively induced apoptosis of the cancer cells, which was related to the co-localization of the nanomicelles with mitochondria; the increase of proapoptotic protein Bax, cytochrome $\mathrm{C}$, and apoptotic enzymes caspase 9 and 3; and the decrease in anti-apoptotic proteins Bcl-2 and Mcl-1. Oral administration of the paclitaxel hybrid nanomicelles manifested the same anticancer efficacy as the intravenous injection of taxol in resistant breast cancerbearing mice. The oral suitability of this formulation was associated with the nanostructure and the actions of TPGS and DQA. In conclusion, the fabricated paclitaxel hybrid nanomicelles represent a promising oral formulation to treat drug-resistant breast cancer.

\section{Acknowledgments}

This work was funded by the National Natural Science Foundation of China (grant numbers 81373343, 81673367) and in part by the Social Development Key Project of Dongguan (grant number 2017507152463).

\section{Disclosure}

The authors report no conflicts of interest in this work. 


\section{References}

1. Gradishar WJ, Tjulandin S, Davidson N, et al. Phase III trial of nanoparticle albumin-bound paclitaxel compared with polyethylated castor oil-based paclitaxel in women with breast cancer. J Clin Oncol. 2005; 23(31):7794-7803.

2. McGuire WP, Hoskins WJ, Brady MF, et al. Cyclophosphamide and cisplatin compared with paclitaxel and cisplatin in patients with stage III and stage IV ovarian cancer. New Engl J Med. 1996;334(1):1-6.

3. Sandler A, Gray R, Perry MC, et al. Paclitaxel-carboplatin alone or with bevacizumab for non-small-cell lung cancer. New Engl J Med. 2006; 355(24):2542-2550.

4. Gelderblom H, Verweij J, Nooter K, Sparreboom A, Cremophor EL. The drawbacks and advantages of vehicle selection for drug formulation. Eur J Cancer. 2001;37(13):1590-1598.

5. Weiss RB, Donehower RC, Wiernik PH. Hypersensitivity reactions from Taxol. J Clin Oncol. 1990;8(7):1263-1268.

6. Shamma RN, Basha M. Soluplus ${ }^{\circledR}$ : a novel polymeric solubilizer for optimization of Carvedilol solid dispersions: Formulation design and effect of method of preparation. Powder Technol. 2013;237: 406-414.

7. Dian LH, Yu EJ, Chen XN, et al. Enhancing oral bioavailability of quercetin using novel soluplus polymeric micelles. Nanoscale Res Lett. 2014;9(1):2406-2416.

8. Wu SH, Hopkins WK. Characteristics of d- $\alpha$-tocopheryl PEG1000 succinate for applications as an absorption enhancer in drug delivery systems. Pharm Tech. 1999;23:52-69.

9. Guo YY, Luo J, Tan SW, Otieno BO, Zhang ZP. The applications of Vitamin E TPGS in drug delivery. Eur J Pharm Sci. 2013;49(2): 175-186.

10. Shieh MJ, Hsu CY, Huang LY, Chen HY, Huang FH, Lai PS. Reversal of doxorubicin-resistance by multifunctional nanoparticles in MCF-7/ADR cells. J Control Release. 2011;152(3):418-425.

11. Feng SS, Mei L, Anitha P, Gan CW, Zhou W. Poly(lactide)-vitamin E derivative/montmorillonite nanoparticle formulations for the oral delivery of docetaxel. Biomaterials. 2009;30(19):3297-3306.

12. Weiss MJ, Wong JR, Ha CS, et al. Dequalinium, a topical antimicrobial agent, displays anticarcinoma activity based on selective mitochondrial accumulation. Proc Natl Acad Sci US A. 1987;84(15): 5444-5448.

13. Zhang Y, Li RJ, Ying X, et al. Targeting therapy with mitosomal daunorubicin plus amiodipine has the potential to circumvent intrinsic resistant breast cancer. Mol Pharm. 2011;8(1):162-175.
14. Ying X, Wen H, Lu WL, et al. Dual-targeting daunorubicin liposomes improve the therapeutic efficacy of brain glioma in animals. J Control Release. 2010;141:183-192.

15. Ramasamy T, Ruttala HB, Gupta B, et al. Smart chemistry-based nanosized drug delivery systems for systemic applications: a comprehensive review. J Control Release. 2017;258:226-253.

16. Ramasamy T, Haidar ZS, Tran TH, et al. Layer-by-layer assembly of liposomal nanoparticles with PEGylated polyelectrolytes enhances systemic delivery of multiple anticancer drugs. Acta Biomater. 2014; 10(12):5116-5127.

17. Matsumura Y, Maeda HA. A new concept for macromolecular therapeutics in cancer chemotherapy: mechanism of tumoritropic accumulation of proteins and the antitumor agent SMANCS. Cancer Res. 1986;46(12 Pt 1):6387-6392.

18. Wang AT, Liang DS, Liu YJ, Qi XR. Roles of ligand and TPGS of micelles in regulating internalization, penetration and accumulation against sensitive or resistant tumor and therapy for multidrug resistant tumors. Biomaterials. 2015;53:160-172.

19. Yu Y, Wang ZH, Zhang L, et al. Mitochondrial targeting topotecanloaded liposomes for treating drug-resistant breast cancer and inhibiting invasive metastases of melanoma. Biomaterials. 2012;33(6): $1808-1820$.

20. Zhang L, Yao HJ, Yu Y, et al. Mitochondrial targeting liposomes incorporating daunorubicin and quinacrine for treatment of relapsed breast cancer arising from cancer stem cells. Biomaterials. 2012;33(2): $565-582$.

21. Yao HY, Ju RJ, Wang XX, et al. The antitumor efficacy of functional paclitaxel nanomicelles in treating resistant breast cancers by oral delivery. Biomaterials. 2011;32(12):3285-3302.

22. Henry-Mowatt J, Dive C, Martinou JC, James D. Role of mitochondrial membrane permeabilization in apoptosis and cancer. Oncogene. 2004;23(16):2850-2860.

23. Ramasamy T, Ruttala HB, Chitrapriya N, et al. Engineering of cell microenvironment-responsive polypeptide nanovehicle coencapsulating a synergistic combination of small molecules for effective chemotherapy in solid tumors. Acta Biomater. 2017;48:131-143.

24. Li N, Zhang CX, Wang XX, et al. Development of targeting lonidamine liposomes that circumvent drug-resistant cancer by acting on mitochondrial signaling pathways. Biomaterials. 2013;34(13):3366-3380.

25. Sundaramoorthy P, Ramasamy T, Mishra SK, et al. Engineering of caveolae-specific self-micellizing anticancer lipid nanoparticles to enhance the chemotherapeutic efficacy of oxaliplatin in colorectal cancer cells. Acta Biomater. 2016;42:220-231.
International Journal of Nanomedicine

\section{Publish your work in this journal}

The International Journal of Nanomedicine is an international, peerreviewed journal focusing on the application of nanotechnology in diagnostics, therapeutics, and drug delivery systems throughout the biomedical field. This journal is indexed on PubMed Central, MedLine, CAS, SciSearch ${ }^{\circledR}$, Current Contents ${ }^{\circledR} /$ Clinical Medicine,

\section{Dovepress}

Journal Citation Reports/Science Edition, EMBase, Scopus and the Elsevier Bibliographic databases. The manuscript management system is completely online and includes a very quick and fair peer-review system, which is all easy to use. Visit http://www.dovepress.com/ testimonials.php to read real quotes from published authors. 